\title{
Potential for molecular targeted therapy of HER-2/neu for invasive bladder cancer: Examination of gene amplification by fluorescence in situ hybridization
}

\author{
YOSHIAKI YAMADA ${ }^{1}$, KATSUYA NARUSE ${ }^{1}$, KOGENTA NAKAMURA $^{1}$, SHIGEYUKI AOKI ${ }^{1}$, \\ TOMOHIRO TAKI ${ }^{1}$, MOTOI TOBIUME ${ }^{1}$, KENJI ZENNAMI ${ }^{1}$, REMI KATSUDA $^{1}$, MIKI HIRANO ${ }^{1}$, \\ KEIKO HAYASHIDA $^{1}$, EMI MIZUMUKAI ${ }^{2}$, HIROSHI NANAURA ${ }^{2}$ and NOBUAKI HONDA ${ }^{1}$ \\ ${ }^{1}$ Department of Urology, Aichi Medical University School of Medicine, Aichi; \\ ${ }^{2}$ Division of Urology, National Health Insurance Sakashita Hospital, Gifu, Japan
}

Received May 2, 2007; Accepted June 15, 2007

\begin{abstract}
Analysis of HER-2/neu gene amplification by fluorescence in situ hybridization was performed in 40 patients with invasive bladder cancer in order to evaluate the potential for molecular targeted therapy of HER-2 as a tailor-made treatment for patients with invasive bladder cancer. This study included 40 patients seen at the Aichi Medical University Hospital from January 2001 to December 2004 and were pathologically diagnosed with invasive transitional cell carcinoma of the bladder (pT2-pT4). The PathVysion kit was used to evaluate the status of HER-2/neu gene amplification, and a signal ratio $\geq 2.0$ was considered positive for HER-2/neu gene amplification. In primary foci 5 patients (12.5\%) were positive for HER-2/neu gene amplification. According to the classification of grade and stage, no statistically significant difference was observed. Lymph node metastasis was found in 10 patients, and 3 patients $(30 \%)$ were positive for HER-2/neu gene amplification. In the patients with HER-2/neu gene-amplified metastatic lymph nodes, primary foci were also positive for gene amplification, showing a statistically significant difference. This study indicates that $12.5 \%$ of patients with invasive bladder cancer may benefit from molecular targeted therapy of HER-2, and that molecular targeted therapy can be expected to be effective even for patients with lymph node metastases as long as their primary foci are positive for HER-2/neu gene amplification.
\end{abstract}

Correspondence to: Dr Yoshiaki Yamada, Department of Urology, Aichi Medical University School of Medicine, Nagakute, Aichi 480-1195, Japan

E-mail: 101959@gk.amu.aichi-med-u.ac.jp

Key words: invasive bladder carcinoma, HER-2/neu, FISH, molecular targeted therapy

\section{Introduction}

Radical cystectomy is currently the standard treatment for invasive bladder cancer without metastasis. However, the results are substantially influenced by the pathological stage and the presence or absence of lymph node metastasis at the time of surgery. The cause-specific survival rate has been reported to be favorable at about $70 \%$ when invasion was observed only in the tunica muscularis (pT2), whereas the rate was $30-40 \%$ when invasion into the surrounding adipose tissue was observed (pT3), and around 20\% when lymph node metastasis was noted (1-3). In addition, after radical cystectomy, most recurrences were distant metastases, only about $10 \%$ being local recurrence (4). Therefore, it is more important to eradicate such micro-metastases that cannot be identified by imaging rather than to increase local curability, to improve the treatment results of radical cystectomy. Surgical resection is not sufficient for invasive bladder cancer with involvement outside the bladder wall or lymph node metastasis, and additional therapy is required.

Multi-drug combination chemotherapy with anti-cancer agents is commonly used to treat progressive bladder cancer that is unresectable or metastatic. M-VAC therapy is a typical chemotherapy regimen and has been the gold standard since Sternberg et al $(5,6)$ reported a response rate of $72 \%$ and complete remission rate of $36 \%$. However, subsequent studies have revealed that the therapy has a low response rate with a short duration of response, which lowers the prospect of long-term survival; there is often concern about dose intensity because a large proportion of the targeted patients are elderly; and the high toxicity of the drug is a substantial physical burden to the many elderly patients with bladder cancer $(7,8)$. Moreover, at present, the standard treatment for M-VACresistant cancer has not been established. Therefore, the development of novel regimens replacing M-VAC therapy is on-going, and clinical trials of anti-cancer agents, mainly gemcitabine and taxane, are being conducted; however, their effectiveness is still under examination (9-11).

Drugs for molecular targeted therapies for cancer are being developed to target changes in genes and molecules that are characteristic of cancer. Conventional anti-cancer 
agents primarily affect the process of nucleic acid, DNA, and microtubule synthesis, and exert anti-tumor effects. These agents, however, have limited effectiveness due to poor tumor selectivity, since they affect both normal and tumor cells. For conventional anti-cancer agents, therefore, the maximum tolerated dose without toxicity has been regarded as the optimal dose. However, molecular targeted therapeutic drugs generally have a weaker toxicity than anti-cancer agents. Moreover, these drugs can be administered safely even to elderly patients, which has been emphasized as an advantage. Furthermore, these drugs can be used in combination with existing anti-cancer agents, and are superior in that they can be used as a tailor-made treatment by coupling them with development of biomarkers.

In this study, we analyzed HER-2/neu gene amplification by fluorescence in situ hybridization (FISH) to determine the potential for molecular targeted therapy of HER-2 as an effective treatment for patients with invasive bladder cancer.

\section{Patients and methods}

Patients. We studied 40 patients who attended Aichi Medical University Hospital from January 2001 to December 2004, and were pathologically diagnosed with invasive bladder transitional cell carcinoma (pT2-pT4). The diagnostic methods were radical cystectomy for 33 patients, and TUR-Bt for 7 patients. The patients were aged 47-80 years (median 65 , mean $65.6 \pm 8.4$ years); 37 were male and 3 were female. The pathological grade was Grade 2 and 3 in 3 and 37 patients, respectively. The stage was pT2, pT3 and pT4, in 29,5 , and 6 patients, respectively. The $\mathrm{N}$ classification was $\mathrm{pN} 0, \mathrm{pN} 1, \mathrm{pN} 2$ and $\mathrm{pNx}$, in $23,4,6$, and 7 patients, respectively. Histopathological grade was based on the World Health Organization (WHO) classification (12), and the TNM classification (13) was used to evaluate primary tumors and lymph node metastases.

This study was approved by the Institutional Review Board at Aichi Medical University (no. 275), and each patient gave an informed consent before FISH analysis. Table I shows the characteristics of the 40 patients.

Fluorescence in situ hybridization (FISH) analysis and evaluation method. In order to test whether amplification of the HER-2/neu gene occurred in bladder carcinoma, a FISH analysis was performed on a representative proportion of the tumors using the Food and Drug Administration (FDA)approved kit, PathVysion (Vysis, Downers Grove, IL, USA). The staining was performed on paraffin sections exactly according to the manufacturer's recommendations. Briefly, deparaffinized slides were treated with a protein-digesting enzyme at $37^{\circ} \mathrm{C}$ for $10 \mathrm{~min}$. Preparations were denatured in $70 \%$ formamide/ $2 \mathrm{X}$ standard saline citrate (SSC), $\mathrm{pH} 7.0$, at $72^{\circ} \mathrm{C}$, for $5 \mathrm{~min}$. Then, a solution containing the HER-2/neu probe coupled with SpectrumOrange and a specific probe for the centromere of chromosome 17 coupled with SpectrumGreen were applied to the tissue sections at $37^{\circ} \mathrm{C}$ for $15 \mathrm{~h}$. After hybridization, the unannealed probe was washed in $2 \mathrm{X} \mathrm{SSC/NP40} 0.3 \%$ at $73^{\circ} \mathrm{C}$ for $2 \mathrm{~min}$. Nuclei were counterstained using a 4,6-diamidine, 2-phenylindol (DAPI)/ antifade solution, and stored in darkness at $8^{\circ} \mathrm{C}$ until
Table I. Patient characteristics.

Patients no.

Age

Average age

$65.6 \pm 8.35$

Median age

Gender

Male

Female

T classification

pT2 22

pT3 13

pT4

5

$\mathrm{N}$ classification

$\begin{array}{lc}\mathrm{pN} 0 & 23 \\ \mathrm{pN} 1 & 4 \\ \mathrm{pN} 2 & 6 \\ \mathrm{pNx} & 7\end{array}$

Grade

G2

G3

37

evaluation. In each preparative run, positive controls (paraffin sections of breast cancers known to be amplified for the HER-2/neu gene or ProbeCheck control slides supplied by the manufacturer) were included. A Leica DMRB microscope equipped with appropriate filters for DAPI, SpectrumGreen and SpectrumOrange was used to score the number of signals per nucleus. Images were captured using a Quantics digital camera (Axioplan 2 imaging, Zeiss, Jena, Germany) and Quips FISH imaging software (Meta Cyte scanning imaga cytometer, Meta Systems, Altlussheim, Germany). The number of fluorescent signals was counted in 60 nuclei of invasive tumor cells in two distant areas of the section for each case. For each tumor, the mean number of signals per nucleus was determined. Amplification was defined by at least a 2-fold excess of the number of copies of the HER-2/neu gene with regard to the number of centromeres of chromosome 17 (Fig. 1).

For statistical analysis, Statistical Package for the Social Sciences (SPSS, Chicago, IL, USA) version 10.0 for Windows software was used. The $\chi^{2}$ test was used to detect statistically significant differences between the groups, with a significance level of $\mathrm{p}<0.05$.

\section{Results}

In primary foci, the signal ratio was $0-1.0$ in 4 patients (10.0\%), $1.1-2.0$ in $31(77.5 \%)$, and $\geq 2.0$, which was considered positive 

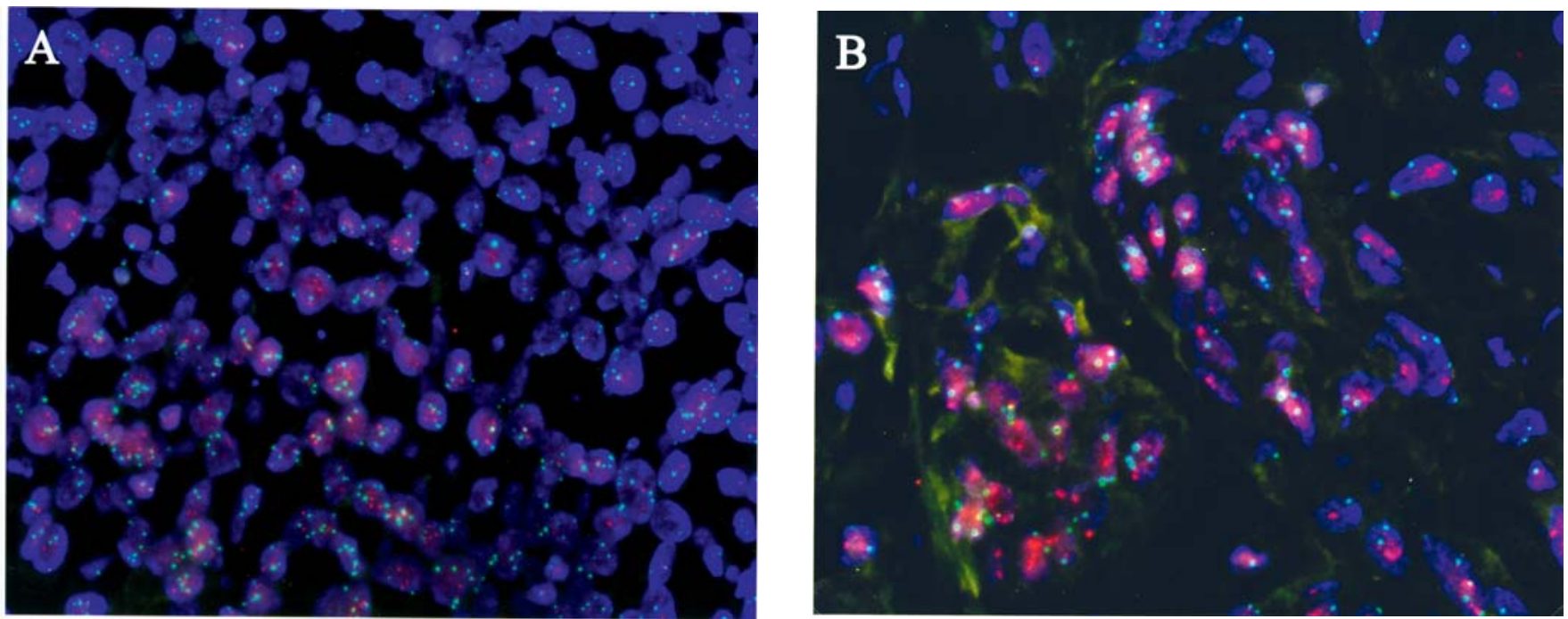

Figure 1. Fluorescence in situ hybridization of HER-2/neu on paraffin-embedded tissue sections (x400). A, Tumor without amplification. A mean number of two signals per nucleus was observed. B, Tumor with a high-level amplification.

Table II. Results of gene amplification by grade and stage.

\begin{tabular}{|c|c|c|c|c|}
\hline & $\begin{array}{c}\text { FISH-A } \\
(\%)\end{array}$ & $\begin{array}{c}\text { FISH-NA } \\
(\%)\end{array}$ & Total & $\mathrm{p}$-value \\
\hline \multicolumn{5}{|c|}{ Grade } \\
\hline G2 & $0 \quad(0)$ & $3(100)$ & 3 & \\
\hline G3 & $5(13.5)$ & $32(86.4)$ & 37 & $>0.99$ \\
\hline \multicolumn{5}{|c|}{$\mathrm{T}$ classification } \\
\hline $\mathrm{T} 2$ & $2 \quad(9)$ & $20(90.9)$ & 22 & \\
\hline $\mathrm{T} 3$ & $2(15.3)$ & $11(84.6)$ & 13 & \\
\hline $\mathrm{T} 4$ & $1(20.0)$ & $4(80.0)$ & 5 & 0.75 \\
\hline \multicolumn{5}{|c|}{$\mathrm{N}$ classification } \\
\hline N1 & $0 \quad(0)$ & $4(100)$ & 4 & \\
\hline $\mathrm{N} 2$ & $3 \quad(50)$ & $3(50)$ & 6 & 0.32 \\
\hline
\end{tabular}

FISH-A, FISH amplified. FISH-NA, FISH not amplified.

for HER-2/neu gene amplification, in 5 (12.5\%). According to the classification of grade, all Grade 2 patients were negative for HER-2/neu gene amplification, but 5 Grade 3 patients were positive $(5 / 37,13.5 \%)(\mathrm{p}=0.99)$. According to the classification of stage, 2 pT2 patients $(2 / 22,9 \%), 2$ pT3 patients $(2 / 13,15.3 \%)$, and 1 pT4 patient were positive $(1 / 5,20 \%)(p=0.75)$. Lymph node metastasis was found in 10 patients, and $3 \mathrm{pN} 2$ patients were positive for HER-2/neu gene amplification $(3 / 6,50 \%)(p=0.32)$. No statistically significant difference was observed among the groups (Table II). In metastatic lymph nodes, the signal ratio was $1.0-2.0$ in 7 patients $(70 \%)$ and $\geq 2.0$ in $3(30 \%)$, and primary foci were positive for HER-2/neu gene amplification as well, which showed a statistically significant difference $(\mathrm{p}=0.02)$ (Table III).
Table III. Gene amplification in primary tumors and lymph node metastases

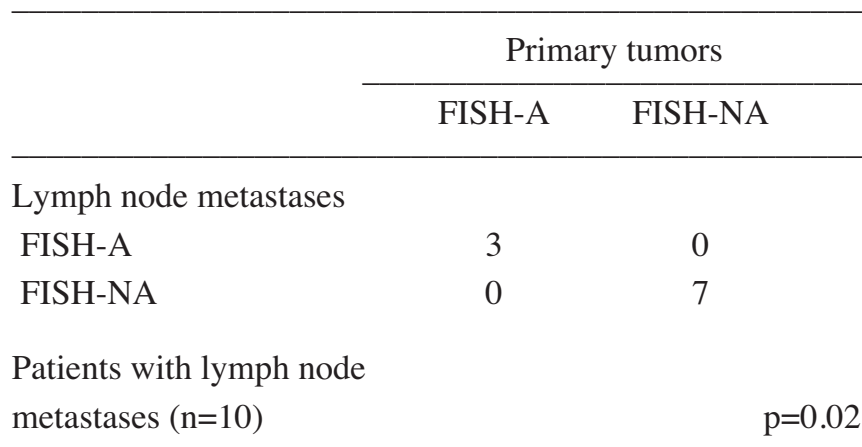

FISH-A, FISH amplified. FISH-NA, FISH not amplified.

\section{Discussion}

HER-2/neu (or HER-2) is a proto-oncogene located at chromosome $17 \mathrm{q} 21$, encoding a protein with a molecular weight of $185 \mathrm{kDa}$ which has a transmembrane receptor structure. This protein is a tyrosine kinase-type cell surface receptor which has amino acid sequences similar to those of an epidermal growth factor receptor, and that cell differentiation and proliferation are stimulated by a ligand binding to an extracellular domain. Moreover, fundamental studies have shown that HER-2 overexpression induces cell transformation and that HER-2-positive tumors are more aggressive. In normal tissues, HER-2 is slightly expressed only in the liver, bile duct, gastrointestinal tract, skin, genital organs and urinary tract, with limited expression in most normal tissues (14-16). Therefore, the potential for molecular targeted therapy of HER-2 is of great interest.

Since Slamon et al (17) reported the correlation between HER-2 (c-erbB-2) gene amplification and breast cancer with a poor outcome in 1987, HER-2 has been considered to be a factor of poor prognosis in breast cancer. In addition, breast 
cancer with HER-2 overexpression has been reported to be resistant to hormone therapy $(18,19)$ resulting in establishment of treatment with trastuzumab (20). Currently, the methods to analyze HER-2 in tissues include analysis of gene amplification, mRNA overexpression, and protein overexpression; however, possible methods for use on formalinfixed paraffin sections are IHC and FISH.

Examination of gene amplification rather than antigen expression is a more reliable method to identify patients with HER-2-positive breast cancer $(21,22)$. Hence, we performed this analysis of gene amplification by FISH using the FDArecommended kit.

Up to 40 studies on HER-2/neu in urothelial cancer have been reported, including analysis by IHC. While HER-2/neu overexpression was observed in $12 \%$ (23) to $71 \%$ (24) of cancers in these studies, this overexpression was correlated with grade and stage in some studies $(25,26)$ but not in others $(27,28)$, suggesting that this field has not yet been established. In our patients with invasive bladder cancer, HER-2/neu overexpression was not correlated with grade, stage, or lymph node metastatic status.

Since accurate methods of determination of HER-2/neu expression in bladder cancer have not been established at present, analysis of HER-2/neu gene amplification by FISH, which has been established in identifying patients with HER-2/neu-positive breast cancer, was performed in this study.

In analysis of HER-2/neu gene amplification by FISH, De Pinieux et al (29) reported that HER-2/neu gene amplification was detected in $28.6 \%(6 / 21)$ of patients with urothelial cancer, while Sauter et al (30) reported that HER-2/neu gene amplification was detected only in 7\% (10/141) of patients with urothelial cancer (36 pTa, 42 pT1, 67 pT2-T3/20 G1, 39 G2, 46 G3 and 6 with grade and stage unknown). In addition, Kruger et al (31) reported that HER-2/neu gene amplification was detected in $5 \%(2 / 42)$ of patients with invasive bladder cancer. In our study, HER-2/neu gene amplification was detected in $12.5 \%(5 / 40)$ of patients with urothelial cancer and in $30 \%(3 / 10)$ of patients with metastasis. The reason for such discrepancy in the frequency of HER-2/neu gene amplification detected by FISH is that HER-2/neu expression is rare among extensive specimens and it may not be detected on a glass slide in some cases because 400-fold magnification is required for observation by FISH, and because there may be a difference within the specimen slides as well. In addition, an automated analysis system may not be able to detect weak signals, and in such cases, analysis by fluorescence microscopy may also be necessary. Moreover, the dose effect caused by polysomy and DNA demethylation should be taken into consideration.

There are few reports on HER-2/neu gene amplification in metastatic lymph nodes in bladder cancer. In analysis by IHC, Gardmark et al (32) reported that $40 \%$ (34/86) of metastatic lymph nodes were HER-2 positive and $72 \%$ of patients (34/47) also had HER-2-positive primary foci. In addition, Wester et al (33) reported that 67\% (14/21) of metastatic lesions were HER-2 positive, and all patients with HER-2-positive metastatic foci also had positive primary foci. However, they also reported that 3 patients (14\%) had negative metastatic foci despite having positive primary foci.
Moreover, they reported that $89 \%$ (8/9) of patients with local metastases were HER-2 positive, while $50 \%$ (6/12) of patients with distant metastases were HER-2 positive, indicating that HER-2 expression tended to vary between local and distant metastases. This finding is interesting, and we consider that it should be examined in a larger number of patients. Our results also showed that 30\% (3/10) of patients with lymph node metastasis were positive for HER-2/neu gene amplification, and in each of these 3 patients, primary foci were positive as well.

Trastuzumab is a human monoclonal antibody against the outer cell membrane of the HER-2 receptor. By binding to the receptor, this drug blocks subsequent signals to the receptor, inhibits cancer growth, and produces an anti-tumor effect, representing a molecular targeted therapeutic drug for HER-2. Our results suggested that $42.5 \%$ of patients with invasive bladder cancer may benefit from this drug, and that it can be expected to be effective for metastatic lymph nodes even in patients with lymph node metastases, as long as their primary tumors are HER-2 positive. Further clinical studies on various phases are needed to establish an effective treatment with trastuzumab for bladder cancer.

\section{References}

1. Bassi P, Ferrante GD, Piazza N, Spinadin R, Carando R, Pappagallo $\mathrm{G}$ and Pagano F: Prognostic factors of outcome after radical cystectomy for bladder cancer: a retrospective study of a homogeneous patient cohort. J Urol 161: 1494-1497, 1999.

2. Ghoneim MA, el-Mekresh MM, el-Baz MA, el-Attar IA and Ashamallah A: Radical cystectomy for carcinoma of the bladder: critical evaluation of the results in 1,026 cases. J Urol 158: 393-399, 1997

3. Waehre H, Ous S, Klevmark B, et al: A bladder cancer multiinstitutional experience with total cystectomy for muscleinvasive bladder cancer. Cancer 72: 3044-3051, 1993.

4. Schuster TG, Smith DC and Montie JE: Pelvic recurrences post cystectomy: current treatment strategies. Semin Urol Oncol 19: 45-50, 2001.

5. Sternberg CN, Yagoda A, Scher HI, et al: Preliminary results of M-VAC (methotrexate, vinblastine, doxorubicin and cisplatin) for transitional cell carcinoma of the urothelium. J Urol 133: 403-407, 1985.

6. Sternberg CN, Yagoda A, Scher HI, et al: Methotrexate, vinblastine, doxorubicin, and cisplatin for advanced transitional cell carcinoma of the urothelium. Efficacy and patterns of response and relapse. Cancer 64: 2448-2458, 1989.

7. Loehrer PJ Sr, Einhorn LH, Elson PJ, et al: A randomized comparison of cisplatin alone or in combination with methotrexate, vinblastine, and doxorubicin in patients with metastatic urothelial carcinoma: a cooperative group study. J Clin Oncol 10: 1066-1073, 1992.

8. Saxman SB, Propert KJ, Einhorn LH, et al: Long-term follow-up of a phase II intergroup study of cisplatin alone or in combination with methotrexate, vinblastine, and doxorubicin in patients with metastatic urothelial carcinoma: a cooperative group study. J Clin Oncol 15: 2564-2569, 1997

9. Bajorin DF, McCaffrey JA, Dodd PM, et al: Ifosfamide, paclitaxel, and cisplatin for patients with advanced transitional cell carcinoma of the urothelial tract: final report of a phase II trial evaluating two dosing schedules. Cancer 88: 1671-1678, 2000.

10. Von der Maase H, Hansen SW, Roberts JT, et al: Gemcitabine and cisplatin versus methotrexate, vinblastine, doxorubicin, and cisplatin in advanced or metastatic bladder cancer: results of a large, randomized, multinational, multicenter, phase III study. J Clin Oncol 18: 3068-3077, 2000.

11. Von der Maase H, Sengelov L, Roberts JT, et al: Long-term survival results of a randomized trial comparing gemcitabine plus cisplatin, with methotrexate, vinblastine, doxorubicin, plus cisplatin in patients with bladder cancer. J Clin Oncol 23: 4602-4608, 2005. 
12. Epstein JI, Amin MB, Reuter VR and Mostofi FK: The world health organization/international society of urological pathology consensus classification of urothelial (transitional cell) neoplasms of the urinary bladder. Am J Surg Pathol 22: 1435-1448, 1998.

13. Sobin LH and Wittekind C (eds): In: TNM Classification of Malignant Tumors. 6th edition. Wiley-Liss, New York, NY, pp199-202, 2002.

14. Natali PG, Nicotra MR, Bigotti A, Venturo I, Slamon DJ, Fendly BM and Ullrich A: Expression of the p185 encoded by HER2 oncogene in normal and transformed human tissues. Int J Cancer 45: 457-461, 1990.

15. Press MF, Cordon-Cardo C and Slamon DJ: Expression of the HER-2/neu proto-oncogene in normal human adult and fetal tissues. Oncogene 5: 953-962, 1990.

16. Gorgoulis VG, Barbatis C, Poulias I and Karameris AM: Molecular and immunohistochemical evaluation of epidermal growth factor receptor and c-erb-B-2 gene product in transitional cell carcinomas of the urinary bladder: a study in Greek patients. Mod Pathol 8: 758-764, 1995.

17. Slamon DJ, Clark GM, Wong SG, Levin WJ, Ullrich A and McGuire WL: Human breast cancer: correlation of relapse and survival with amplification of the HER-2/neu oncogene. Science 235: 177-182, 1987.

18. Slamon DJ, Godolphin W, Jones LA, et al: Studies of the HER$2 /$ neu proto-oncogene in human breast and ovarian cancer. Science 244: 707-712, 1989.

19. Press MF, Bernstein L, Thomas PA, et al: HER-2/neu gene amplification characterized by fluorescence in situ hybridization: poor prognosis in node-negative breast carcinomas. J Clin Oncol 15: 2894-2904, 1997.

20. Slamon DJ, Leyland-Jones B, Shak S, et al: Use of chemotherapy plus a monoclonal antibody against HER2 for metastatic breast cancer that overexpresses HER2. N Engl J Med 344: 783-792, 2001

21. Mass RD, Press MF, Anderson S, et al: Evaluation of clinical outcomes according to HER-2 detection by fluorescence in situ hybridization in women with metastatic breast cancer treated with trastuzumab. Clin Breast Cancer 6: 240-246, 2005.

22. Dybdal N, Leiberman G, Anderson S, et al: Determination of HER2 gene amplification by fluorescence in situ hybridization and concordance with the clinical trials immunohistochemical assay in women with metastatic breast cancer evaluated for treatment with trastuzumab. Breast Cancer Res Treat 93: 3-11, 2005.
23. Lipponen P, Eskelinen M, Syrjanen S, Tervahauta A and Syrjanen K: Use of immunohistochemically demonstrated cerbB-2 oncoprotein expression as a prognostic factor in transitional cell carcinoma of the urinary bladder. Eur Urol 20: 238-242, 1991.

24. Gandour-Edwards R, Lara PN Jr, Folkins AK, et al: Dose HER2/neu expression provide prognostic information in patients with advanced urothelial carcinoma? Cancer 95: 1009-1015, 2002.

25. Miyamoto H, Kubota Y, Noguchi S, et al: c-erb-2 gene amplification as a prognostic marker in human bladder cancer. Urology 55: 679-683, 2000.

26. Wright C, Mellon K, Neal DE, Johnston P, Corbett IP and Horne $\mathrm{CH}$ : Expression of c-erbB-2 protein product in bladder cancer. Br J Cancer 62: 764-765, 1990.

27. Ioachim E, Charchanti A, Stavropoulos NE, Skopelitou A, Athanassiou ED and Agnantis NJ: Immunohistochemical expression of retinoblastoma gene product $(\mathrm{Rb}), \mathrm{p} 53$ protein, MDM2, c-erbB-2, HLA-DR and proliferation indices in human urinary bladder carcinoma. Histol Histopathol 15: 721-727, 2000.

28. Koyuncuoglu M, Kargi A, Cingoz S and Kirkali Z: Investigation of p53, c-erbB-2, PCNA immunoreactivity, DNA content, AgNOR and apoptosis in bladder carcinoma as prognostic parameters. Cancer Lett 126: 143-148, 1998.

29. De Pinieux G, Colin D, Vincent-Salomon A, Couturier J, Amsellem-Ouazana D, Beuzeboc P and Vieillefond A: Confrontation of immunohistochemistry and fluorescence in situ hybridization for the assessment of HER-2/neu (c-erbB-2) status in urothelial carcinoma. Virchows Arch 444: 415-419, 2004.

30. Sauter G, Moch H, Moore D, et al: Heterogeneity of erbB-2 gene amplification in bladder cancer. Cancer Res 53: 2199-2203, 1993.

31. Kruger S, Weitsch G, Buttner H, et al: Overexpression of cerbB-2 oncoprotein in muscle-invasive bladder carcinoma: relationship with gene amplification, clinicopathological parameters and prognostic outcome. Int J Oncol 21: 981-987, 2002.

32. Gardmark T, Wester K, De la Torre M, Carlsson J and Malmstrom PU: Analysis of HER2 expression in primary urinary bladder carcinoma and corresponding metastases. BJU Int 95: 982-986, 2005.

33. Wester K, Sjostrom A, De la Torre M, Carlsson J and Malmstrom PU: HER-2 - a possible target for therapy of metastatic urinary bladder carcinoma. Acta Oncol 41: 282-288, 2002 . 